\title{
Student Reciprocal Peer Teaching as a Method for Active Learning: An Experience in an Electrotechnical Laboratory
}

\author{
Miguel A. Muñoz-García • Guillermo P. Moreda • \\ Natalia Hernández-Sánchez • Vanesa Valiño
}

(C) Springer Science+Business Media New York 2012

\begin{abstract}
Active learning is one of the most efficient mechanisms for learning, according to the psychology of learning. When students act as teachers for other students, the communication is more fluent and knowledge is transferred easier than in a traditional classroom. This teaching method is referred to in the literature as reciprocal peer teaching. In this study, the method is applied to laboratory sessions of a higher education institution course, and the students who act as teachers are referred to as "laboratory monitors." A particular way to select the monitors and its impact in the final marks is proposed. A total of 181 students participated in the experiment, experiences with laboratory monitors are discussed, and methods for motivating and training laboratory monitors and regular students are proposed. The types of laboratory sessions that can be led by classmates are discussed. This work is related to the changes in teaching methods in the Spanish higher education system, prompted by the Bologna Process for the construction of the European Higher Education Area
\end{abstract}

Keywords Electrical Engineering education .

Student experiments · Active learning .

Reciprocal peer teaching $\cdot$ Laboratory monitor

M. A. Muñoz-García $(\bowtie) \cdot$ G. P. Moreda ·

N. Hernández-Sánchez

Department of Rural Engineering, Technical University

of Madrid, 28040 Madrid, Spain

e-mail: miguelangel.munoz@upm.es

V. Valiño

Department of Energy Systems, Technical University of Madrid,

28003 Madrid, Spain

\section{Introduction}

Active Learning and the Practical Part of a Course

Active learning can be defined as a learning method where students participate as their own teachers or as the teachers for other classmates. Previous studies have shown the benefits of active learning or dynamic training elements; students take an active role in their education and stay motivated, which greatly increases class participation (Krouk and Zhuravleva 2009). The Roman philosopher Luicius Annaeus Seneca (4 BC-AD 65) advocated cooperative learning as early as 2,000 years ago through such statements as, "Qui Docet Discet," or "those who teach learn." However, active learning methods still tend not to be widely applied.

This paper proposes the incorporation of laboratory sessions in engineering courses and also the use of reciprocal peer teaching to engage students and make classes more active. Previous studies have highlighted the importance of laboratory sessions; in a study on the application of a set of activities intended to develop generic competences in their students, Allen and Boraks (1978) found that the implementation of laboratory sessions resulted in students obtaining high marks. In addition to the increase in academic efficiency, these sessions were partly responsible for the decrease in the school dropout rate. More recently, Lin and Tsai (2009) revealed that students who prefer the laboratory method to lectures are more interested in "increasing one's knowledge," which supports the argument for the incorporation of active learning methods to motivate students. Goubeaud (2009) stated that "students learn when they construct their own understanding" and this mode of learning will be enhanced if a method that implements mutual learning is used. 
This paper argues that in current Engineering Studies and in the related degrees that are being implemented, theoretical classes, such as lectures or seminars, should be accompanied by practical classes to reinforce the theoretical teachings. Practical classes have gained recognition for their pedagogical potential in recent years; when acting as supplements to theoretical classes, they reinforce the theoretical learning (Fólder et al. 2011). Reconciling common sense with formalism is not always viewed as necessary or plausible for students to accomplish (Gupta and Elby 2011). Laboratory sessions help to reconcile physics knowledge with common sense.

However, the implementation of laboratory sessions is not enough to ensure active participation. Even in the case of courses that include a laboratory component, classes tend to acquire a passive atmosphere. Typical laboratory sessions build upon the concepts students have developed through home-readings of the laboratory instructions and sometimes answering comprehension questions. These assignments can be considered passive learning, and consequently, it is quite common that only a few students complete the laboratory, while the rest simply copy the answers. The work loses its meaning and becomes merely a mechanical repetition of what is written in the laboratory instructions. In the worst case, as classes are divided during laboratory sessions into groups of two or three students, one individual carries out the assignment while his/her partners follow along passively. Magdalena et al. (2008) referred to this as "parasitism."

This paper studies the potential of the introduction of a student monitor in laboratory sessions to foster active class participation. A "laboratory monitor" is defined here as a student selected to be partially responsible for directing his or her fellow students in the laboratory. This practice is a concept derived from the reciprocal peer teaching method (RPT) and has been supported by the study of Allen and Boraks, who suggested that laboratories could be improved by introducing the figure of the student monitor. The selfdirected learning strategy of using monitors results in the concepts being better understood (Jiusto and Dibiasio 2006).

\section{The Bologna Process}

Higher education in Europe has undergone significant changes in the past few years. The Bologna Process, which began in 1999, called for the formation of the European Higher Education Area (EHEA) with the purpose of creating a standardized higher education system throughout most European countries. The new education system is based on a standardized credit system called European Credit Transfer System (ECTS). Each credit corresponds to between 25 and $27 \mathrm{~h}$ of students' work. In total, 240
ECTSs are required for a Bachelor's and an additional 60 ECTS for a Master's degree. This usually results in a 4-year Bachelor's degree and a 1-year Master's degree.

Along with the changes in the duration of each degree, Bologna principles also establish a new concept for the learning process, moving from a teacher-centered approach to a student-centered method (Cano 2011). The objective of this study, that is, the incorporation of active learning techniques in the class room, is consistent with this concept. Active comprehension is an important aspect of the EHEA model of education (de la Hoz i Casas and de Blas del Hoyo 2009). The recommendation for the ECTS is that more than $50 \%$ of the hours should be dedicated to activities apart from class time. When planning the course, the teacher should account for the time that is to be dedicated outside the classroom to studying, completing practice exercises, and searching for information or completing tasks proposed by the teacher. This new organization has resulted in a shorter and more practical path of study in most cases.

\section{The Experience of Students as Teachers}

This study was carried out at one of the Engineering Schools of the Technical University of Madrid (Spain), which is dedicated to the studies of agronomical engineering. At present, the institution is involved in a process of change in accordance with the Bologna Process. In order to evaluate the laboratory monitor method, an experiment involving students teaching their classmates was carried out. This experiment was undertaken during the 2009-2010 and 2010-2011 course years in the Electrotechnical Laboratory.

The Electrotechnics course was mandatory in the four specialities of the study plans. Prior to the experiment reported here, no laboratory sessions were undertaken in any of the specialities, which was partially due to a lack of means. In the future, all students will have laboratory sessions, given that it has been shown that fusing theory and practice are essential for the understanding of this type of course (Swart 2010). The laboratory is important for the student's conceptual understanding but it is not enough the performance of classic practices as it has been demonstrated that demonstration laboratory and hands-on laboratory do not pose a significant difference in terms of conceptual understanding (McKee et al. 2007).

The use of laboratory monitors in laboratory sessions is proposed to meet the objectives of the EHEA model of education, to increase active learning, and to reinforce the theoretical lessons. This method is derived from the RPT method, wherein students alternate roles as teacher and learner (Bentley and Hill 2009). Reciprocal peer teaching 
method (RPT) has been applied in several educational areas with varying success (Johnson et al. 1998). Although in existence for thousands of years, RPT is an underutilized, yet highly valuable resource for higher education that has been tested by research such as by Chatterjee et al. (2011) that encouraged teamwork and peer-to-peer learning during the course, rather than teacher-centric learning. These authors concluded that RPT fosters development of professional skills such as communication and oral presentation, teamwork, decision-making, leadership, confidence, and respect for peers.

The method tested in our work consisted of a selection of students from a particular group helping their classmates to accomplish the practical part of the course according to the next scheme:

1. Prior to each laboratory session, all students took an examination to test their comprehension of the part of the course related to the laboratory.

2. Those students who passed the exam had the opportunity to become laboratory monitors during the next session. When the examination was passed by more students than monitor vacancies, those with higher marks were selected. The mark obtained in the exam by a monitor was a part of his/her final marks.

3. Before becoming monitors, the selected students were trained by the professor to help the rest of the students. The professor was present both during the preparation and during the practical classes themselves, in order to monitor the students' performances.

Each class had 25-30 students and was divided into small laboratory groups of one or two students. A laboratory monitor was assigned to assist one of these groups. In some cases, such small groups were not possible and the monitor assisted a group of three students.

It was decided that the experiment would be carried out in two of the specialities, while the two other specialities would act as control groups, continuing with the same methodology as before. A total of 181 students were evaluated in this experiment: the specialities " $A$ " and "B" participated in laboratory sessions with monitors and specialities "C" and "D" did not complete any laboratory sessions.

Table 1 shows the distribution of the students participating in the evaluation of the method. Only those students who took the final exam were included in the results.

The monitors conducted each laboratory three times: once while preparing it with the professor's assistance and twice as teachers for their classmates. Through this process, the monitors achieved a high comprehension level of the laboratory and also had the opportunity to gain communication skills. In cases when they finished the laboratory before the class ended, they used the rest of the time to
Table 1 Number of students that participated in the test

\begin{tabular}{llrrrr}
\hline Course & & \multicolumn{2}{l}{ Speciality } & & \\
\cline { 3 - 6 } & & A & B & C & D \\
\hline $2009-10$ & Monitor & 8 & 9 & 0 & 0 \\
$2010-11$ & & 15 & 10 & 0 & 0 \\
$2009-10$ & Non-monitor & 26 & 12 & 18 & 12 \\
$2010-11$ & & 22 & 6 & 25 & 18 \\
TOTAL & \multirow{2}{*}{181} & 71 & 37 & 43 & 30 \\
\hline
\end{tabular}

propose improvements and changes to the laboratory sessions. Teachers could also detect the best way to conduct the practices, an important aim for teachers having a strong engineering orientation (Barak and Shachar 2008).

The final marks for all the students were formed by a theoretical part $(50 \%)$ and a practical part $(50 \%)$. The marks for the theoretical part were obtained in a theoretical final examination. The marks for the practical part were obtained by solving problems in a final examination. As an extra motivation, those students who chose to work as monitors were rewarded for their participation by being exempt from the theoretical final examination.

\section{Experimental Results and Discussion}

The marks of monitors, regular students who had participated in laboratory sessions, and other students who had not had laboratories were evaluated in order to obtain objective data. To complement this information, students in the groups that had laboratory sessions completed a survey. In this way, both quantitative as well as qualitative criteria were taken into account. The results of the students from different specialities are discussed below. The marks should be compared between the specialities, as they are a relative indicator.

Figure 1 shows the comparison between the average marks of the four specialities during the 2 years of the test. The A and B specialities had laboratory sessions with monitors and $\mathrm{C}$ and $\mathrm{D}$ did not have any sort of laboratory sessions. The final examination was divided into a theoretical and a practicum part. The theoretical part was formed by short questions, and the practicum part consisted of four problems to be solved during a timed period. The whole examination was mandatory for every student except the monitors, whose theoretical marks were achieved through the pretest passed to become a monitor.

It must be noted that the global mark, which was the final mark obtained by the student, was the sum of the theoretical and practicum marks. It can be observed that specialities A and B obtained better marks on the examinations. The marks obtained by students of speciality $\mathrm{D}$ 


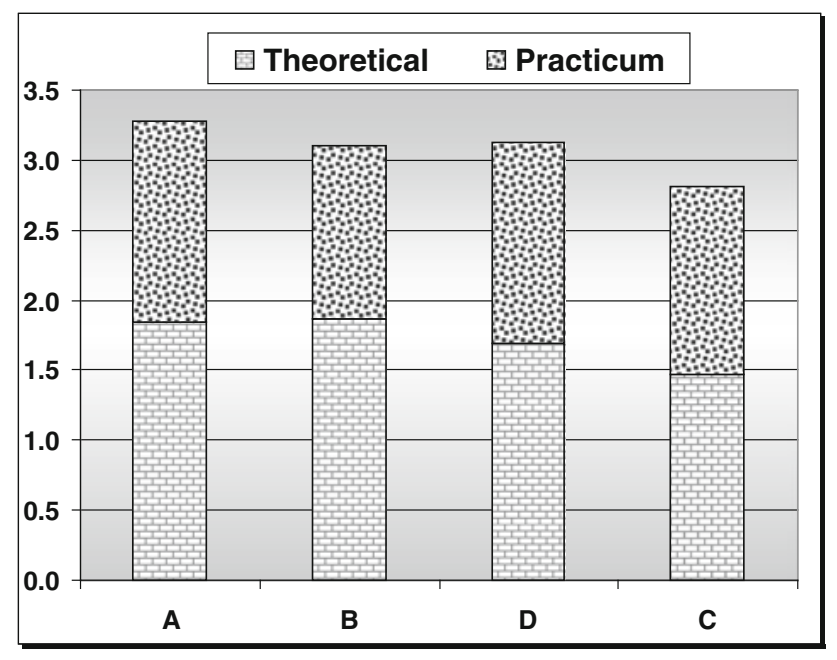

Fig. 1 Results of the final examination by speciality

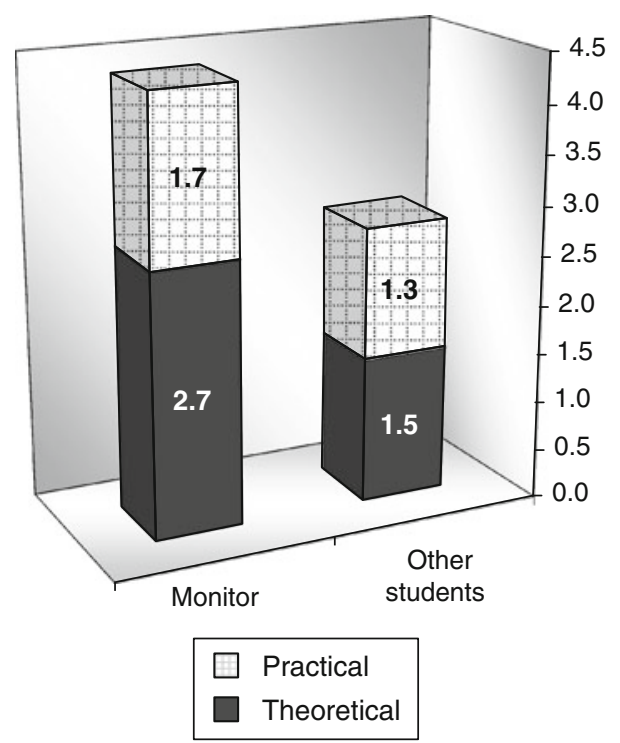

Fig. 2 Results of the final examination for specialty A

were close to those of students of specialities A and B. According to the student's comments in the survey that they filled in, it can be related to the fact that students of speciality D tend to be more interested in the course than the students of the rest of the specialities.

To isolate the influence of being a monitor, Figs. 2 and 3 show the specific results of specialities $\mathrm{A}$ and $\mathrm{B}$, respectively. In these graphs, the data are separated for monitors and the rest of students. It can be observed in both specialities that students who acted as monitors obtained better marks not only in the theoretical part (marks of the pretest passed to become a monitor) but also in the practicum part of the final exam; thus, their total marks were higher.

Apart from the discussed examination marks, a survey was filled out by all the students who completed

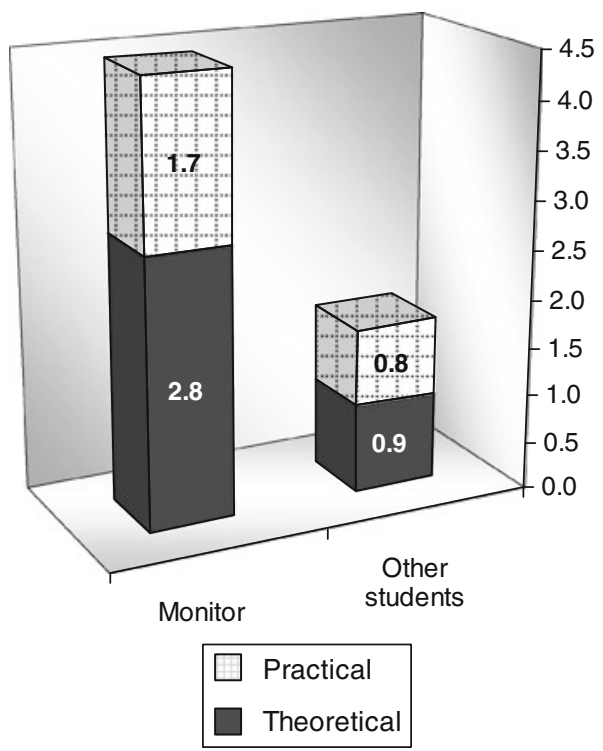

Fig. 3 Results of the final examination for specialty B

Table 2 Survey questions answered by students who attended the labs

Q1 Laboratories were useful for the course.

Q2 The number of laboratories was enough.

Q3 The content of the laboratories was appropriate.

Q4 Laboratories should not have been mandatory.

Q5 The monitor method was helpful.

Q6 Did you participate or try to participate as a monitor?

Q7 A test was necessary before the laboratory sessions.

Q8 I understood the subject better after the laboratory sessions.

Q9 The laboratories were better than I had expected.

Q10 The monitors selection process was fair.

Q11 I understood the laboratory better when it was explained by a classmate.

Q12 Monitors were correctly trained.

Q13 The laboratory equipment was adequate.

Q14 The number of students in the laboratory groups was too high.

laboratories, including monitors and regular students. Table 2 shows the questions of the survey.

The students were asked to answer the survey by assigning a mark from 0 (totally disagree) to 5 (totally agree) to each question. The survey was anonymous, and a space was available at the end where students were asked to freely express their feelings about the experience. This open-ended section provided important subjective information from the students.

Figure 4 summarizes the answers of the students. It can be observed that most students were not only in favor of 


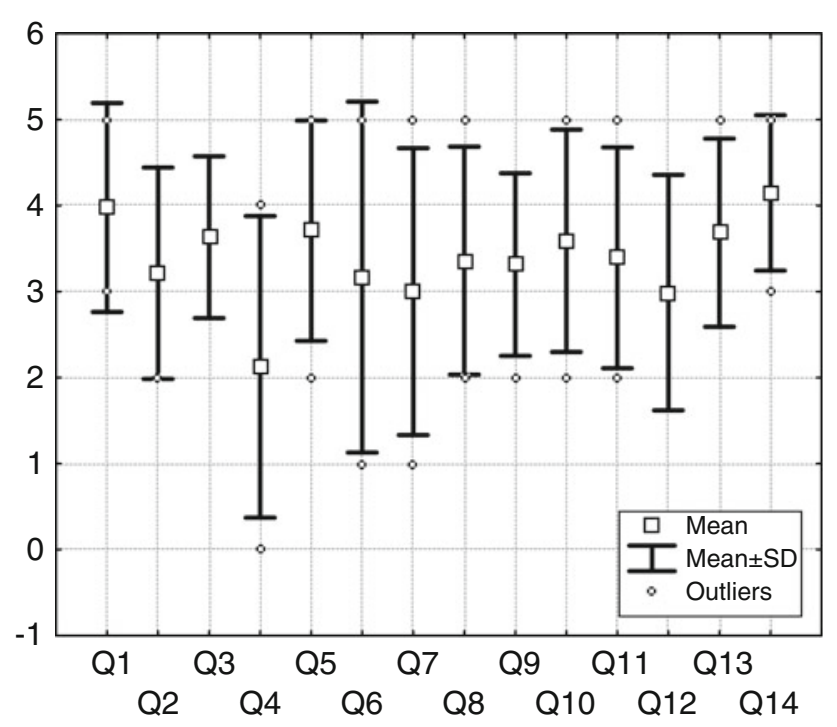

Fig. 4 Answers to all the survey questions filled out by the students

The monitor method was helpful.

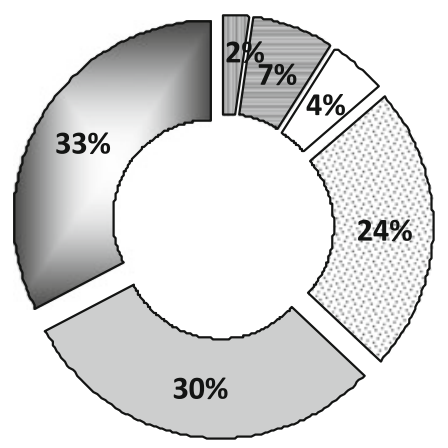

$\square$ Totally disagree
$\square$ Strongly disagree
$\square$ Slightly disagree
$\square$ Slightly agree
$\square$ Strongly agree
$\square$ Totally agree

Fig. 5 Answers for Q5 of the survey. (Don't know $0 \%$ )

\section{I understood the subject better after the lab sessions.}

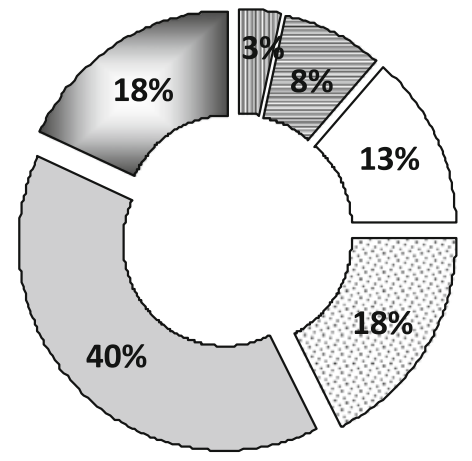

$\square$ Totally disagree
目 Strongly disagree
$\square$ Slightly disagree
$\square$ Slightly agree
$\square$ Strongly agree
$\square$ Totally agree

Fig. 6 Answers for Q8 of the survey. (Don't know $0 \%$ )

having laboratory sessions but also of the laboratory monitor method. Figures 5, 6 and 7 represent the distribution of the answers for questions Q5, Q8, and Q11,

\section{I understood the lab better when it was explained by a classmate.}

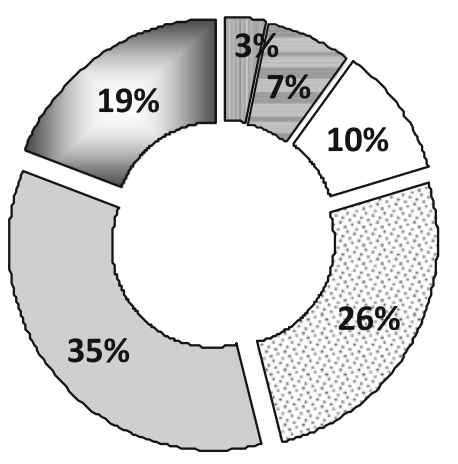

$\square$ Totally disagree

$\square$ Strongly disagree

$\square$ Slightly disagree

$\square$ Slightly agree

$\square$ Strongly agree

$\square$ Totally agree

Fig. 7 Answers for Q11 of the survey. (Don't know $0 \%$ )

which have been considered of special interest as they are directly related to the method. Around $80 \%$ of students expressed agreement with the method.

Apart from the numerical data discussed above, the survey provided student opinions and suggestions. Most of them were positive about the new mechanism tested in the sense that they have better understood the course. Nonetheless, some students expressed disagreement with the system used for the selection of the monitors. Their argument was that the test before the laboratory sessions did not serve as an adequate measure of students' preparedness to be monitors. This complaint can also be understood as a positive reaction to the monitor system, given that it shows interest in participating, and in the future, a higher number of students could be included as monitors.

\section{Conclusions}

According to the results of this study, the teaching system based on self-learning and reciprocal peer teaching between students is considered strongly beneficial for achieving the objectives of the Electrotechnics course in higher education. Students generally pay more attention and perform higher when a monitor explains the laboratory session to them.

The reciprocal peer teaching system does not reduce the necessity for professors. It usually requires extra work for selecting and training the monitors. Hence, students receive more individual attention, the professor solves more advanced queries from the monitors, and monitors solve easier questions from their classmates.

Performing a pretest is one way to select students who are most prepared to act as monitors. However, as students expressed in the survey, this method may exclude students who have little experience in the course material but who 
could nonetheless be trained to be monitors. The selection system should not only test specific area knowledge but also student motivation. Offering a reward to students who act as monitors, such as their exemption from the final exam, motivates them to work; they, in turn, motivate their fellow student.

Practices related to electricity may pose problems in terms of safety. This can present a handicap in the application of the reciprocal peer teaching method. The solution is to divide the laboratory sessions by risk levels, having the student-led segment of the class work with reduced voltage. By dividing the class this way, the risks involved in electrical laboratories is minimal, and the most complicated parts are directly supervised by the professor.

When dividing the class into laboratory groups, it is desirable to create groups of students who have both affinities and also different interests in order for students to collaborate, challenge each other, and enrich each other's understanding (McNair et al. 2011).

Monitors and regular students are more motivated when this method is implemented. The monitor system will be applied regularly in the course to reinforce the new conceptualization of education fostered by the Bologna Process in Europe.

Acknowledgments We want to thank to Sophie Feintuch, Erasmus Mundus Master's Student from Vassar College, for her contributions and corrections, and to the students and professors that participated in the experiment.

\section{References}

Allen AR, Boraks N (1978) Peer tutoring: putting it to the test. Read Teacher 32(3):274-278

Barak M, Shachar A (2008) Projects in technology education and fostering learning: the potential and its realization. J Sci Educ Technol 17(3):285-296. doi:10.1007/s10956-008-9098-2

Bentley BS, Hill RV (2009) Objective and subjective assessment of reciprocal peer teaching in medical gross anatomy laboratory. Anat Sci Educ 2:143-149
Cano MD (2011) Student's involvement in continuous assessment methodologies: a case study for a distributed information system course. IEEE Trans Educ 54(3):442-451

Chatterjee B, Dey D, Chakravorti S (2011) A modular approach for teaching partial discharge phenomenon through experiment. IEEE Trans Educ 54(3):410-415. doi:10.1109/TE.2010.2063432

de la Hoz i Casas J, de Blas del Hoyo A (2009) Learning by doing' methodology applied to the practical teaching of electrical machines. Int J Electr Eng Educ 46(2):133-149

Fólder RM, Brent R, Prince MJ (2011) Engineering instructional development: programs, best practices and Recommendations. J Eng Educ 100(1):89-122

Goubeaud K (2009) How is science learning assessed at the postsecondary level? Assessment and grading practices in college biology, chemistry and physics. J Sci Educ Technol 19(3):237-245. doi:10.1007/s10956-009-9196-9

Gupta A, Elby A (2011) Beyond epistemological deficits: dynamic explanations of engineering students' difficulties with mathematical sense-making. Int J Sci Educ, doi: 10.1080/09500693. 2010.551551

Jiusto S, Dibiasio D (2006) Experiential learning environments: do they prepare our students to be self-directed, life-long learners? J Eng Educ, pp. 195-204

Johnson DW, Johnson RT, Smith KA (1998) Active learning: cooperation in the college classroom. Interaction Book Co, Edina

Krouk BI, Zhuravleva OB (2009) Dynamic training elements in circuit theory course to implement a self-directed learning process. IEEE Trans Educ 52(3):394-399

Lin C, Tsai C (2009) The relationships between students' conceptions of learning engineering and their preferences for classroom and laboratory learning environments. J Eng Educ, pp. 194-204

Magdalena R, Serrano AJ, Martin-Guerrero JD, Rosado A, Martinez M (2008) A teaching laboratory in analog electronics: changes to address the bologna requirements. IEEE Trans Educ 51-4: 456-460. doi:10.1109/TE.2007.912553

McKee E, Williamson VM, Ruebush LE (2007) Effects of a demonstration laboratory on student learning. J Sci Educ Technol 16(5):395-400. doi:10.1007/s10956-007-9064-4

McNair LD, Newswander C, Boden D, Borrego M (2011) Student and faculty interdisciplinary identities in self-managed teams. J Eng Educ 100(2):374-396

Swart AJ (2010) Does it matter which comes first in a curriculum for engineering students-theory or practice?". Int J Electr Eng Educ 47(2):189-199 